\title{
Physical Activity and Sports Participation Associates With Cognitive Functioning and Academic Progression: An Analysis Using the Combined 2017-2018 National Survey of Children's Health
}

\author{
Ryan D. Burns, Yang Bai, and Timothy A. Brusseau
}

\begin{abstract}
Background: The purpose of this study was to examine the independent and joint associations between physical activity (PA) and sports participation on academic performance variables within a representative sample of children and adolescents. Methods: Data were analyzed from the combined 2017-2018 National Survey of Children's Health. Household addresses were randomly selected within each US state. One household parent answered health and wellness questions pertaining to one randomly selected household child ( $\mathrm{N}=37,392 ; 48.1 \%$ female; 6- to $17-\mathrm{y}$ old $)$. Weighted logistic regression models were employed to examine the independent and joint associations between child PA frequency and sports participation with academic performance variables, adjusting for child- and family-level covariates. Results: Child PA frequency independently associated with $37 \%$ to $46 \%$ lower odds and child sports participation independently associated with 53\% lower odds of reported difficulty concentrating, remembering, or making decisions $(P<.001)$. For children who participated in sports, PA associated with $47 \%$ to $56 \%$ lower odds of ever repeating a grade level $(P=.01)$. Conclusions: Frequency of weekly PA and sports participation independently and negatively associated with difficulty concentrating, remembering, and making decisions, whereas the negative association between PA and ever repeating a grade level differed by child sports participation status.
\end{abstract}

Keywords: adolescent, behavioral science, pediatrics, survey research

Higher levels of physical activity (PA) have consistently been shown to positively associate with a variety of academic performance factors, including cognitive functioning, academic behavior, and school grades. ${ }^{1-3}$ The PA, particularly of higher intensities, manifests physiological mechanisms at the cellular, molecular, and structural level of the brain to improve cognitive skills, ${ }^{4}$ including enhancement of neurogenesis and central nervous system metabolism..$^{5}$ In addition to impacting physiological mechanisms that may improve cognitive skills, ${ }^{6-8}$ PA may also impact behavior in the academic classroom. ${ }^{9-12}$ Potential mechanisms for these positive effects on behavior may be due to moderating psychological arousal yielding an internal psychological state conducive for learning, possibly supplementing other physiological, cognitive, emotional, and learning mechanisms. ${ }^{13}$

Although the links between PA and academic performance have been relatively well studied, much less is known regarding the independent association between sports participation and academic performance. Sport is an organized contest or game in which people do certain PAs according to a specific set of rules to compete against each other. In other words, sport participation includes structured PAs characterized by specific rules and regulations. ${ }^{14}$ Sport participation also provides exposure to social factors that are often not present during unstructured PA. Sports participation provides opportunities to enhance task-specific self-efficacy, personal enjoyment, prosocial behavior, and a sense of social support from coaches and teammates. ${ }^{15,16}$ These characteristics of sport participation may lead to improvements in specific aspects of academic performance

The authors are with the Department of Health and Kinesiology, The University of Utah, Salt Lake City, UT, USA. Burns (ryan.d.burns@utah.edu) is corresponding author. above and beyond that provided by other modes of PA. ${ }^{17,18}$ However, a paucity of work has compared both PA and sports participation on various aspects of academic performance variables while also controlling for important factors at both the child and family level.

The yearly administered National Survey of Children's Health (NSCH) collects a variety of child- and family-level information using a representative sample of US children and adolescents. ${ }^{19,20}$ Specifically, the NSCH collects information pertaining to child physical and mental health, child schooling (including indicators of academic performance), the reported weekly frequency of a child meeting the 60 minutes of daily PA recommendation, and whether or not a child has participated in sports during the past 12 months. ${ }^{19,20}$ The NSCH also collects important information pertaining to the family, including adult education, family Federal Poverty Level (FPL), and the family structure, all of which may influence PA, sports participation, and/or academic performance. ${ }^{21-26}$ To the authors' knowledge, no study has examined the independent and joint associations between PA and sports participation in multiple variables related to academic performance while concurrently controlling for important potential confounding factors at both the child and family levels. Therefore, the purpose of this study was to examine the independent and joint associations between PA and sports participation on academic performance variables within a representative sample of children and adolescents from the combined 2017-2018 NSCH.

\section{Methods}

\section{Participants}

The participants were a nationally representative sample of children and adolescents from the United States, aged 6- to 17-years 
old, whose parents completed either the 2017 or the 2018 NSCH. The NSCH is a national survey that is fielded annually by the US Census Bureau and provides data on multiple aspects of child and adolescent health and well-being. The data for the 2017 and 2018 $\mathrm{NSCH}$ were combined to provide opportunities for analyses using variables with small sample sizes or low prevalence. A total of 52,129 surveys were completed for 2017 and 2018 combined, with 21,599 surveys completed in 2017 and 30,530 completed in 2018 for children aged 0-17 years. The overall weighted response rate was $37.4 \%$ for 2017 and $43.1 \%$ for 2018. Children younger than 6 years old were omitted from the current study because PA, sports participation, and academic performance variables were only collected for children who were 6- to 17-years old. Data from a total of 37,392 children and adolescents $(48.1 \%$ female; 6- to $11-\mathrm{y}$ old $=15,896,12$ - to $17-\mathrm{y}$ old $=21,496$ ) were used in the current study. The NSCH data collection does not undergo an external institutional review board review. Instead, the process for the review of methods and procedures for the NSCH was incorporated into the responsibilities of the US Census Bureau and Office of Management and Budget officials. ${ }^{19,20}$

\section{Procedures}

Randomly selected US household addresses were mailed instructions to access the NSCH online. Addresses were randomly selected within each US state and the District of Columbia. After 2 reminder letters and postcard reminders to complete the NSCH online, households that had not accessed the online survey were mailed a paper screening questionnaire. ${ }^{19,20}$ An adult within the household was asked to complete a web or paper screener questionnaire to identify all children 0- to 17-years old who were living in the household. If a child or children were reported to live in the household, adult participants were directed to a detailed age- and web-based topical questionnaire for one randomly selected household child. Adult respondents completed 1 of 3 versions of the survey depending on the child's age: $0-5$ years, $6-11$ years, and $12-17$ years. The survey topics included child and family demographics, child physical and mental health status, family health and activities, and parental health status, among others. Based on web keystroke data and paper cognitive testing, the estimated survey length for households without children was 5 minutes, and the estimated survey length for households with children was 39 minutes. ${ }^{19,20}$

\section{Data Processing}

The 2017-2018 NSCH combined data set contained 2 stratum identifiers corresponding to the state of residence and an identifier corresponding to households flagged with children. ${ }^{19,20}$ The 20172018 NSCH combined data set also included an adjusted probability weight variable that accounted for combining 2 years of data. ${ }^{19,20}$ Missing values for child demographic variables were imputed using hot-deck imputation, and the adult education, household size, and poverty ratio missing values were imputed using sequential regression imputation methods. ${ }^{19,20}$

The dependent variables were 2 items on the $\mathrm{NSCH}$ that aligned with cognitive functioning and academic progression, which both constitute an academic performance. Aligned with cognitive functioning, an item asked if the child has had "Serious difficulty concentrating, remembering, or making decisions because of a physical, mental, or emotional condition?" and was binary coded $(0=$ no; $1=$ yes $)$. Academic progression aligned with an item on the NSCH that asked about ever repeating a grade level,
"Since starting kindergarten, has this child repeated any grades?" which was binary coded $(0=$ no; $1=$ yes $)$. Repeating a grade level is a measure of academic achievement, as achieving a passing grade is needed for progression within US schools.

The primary predictor variables were 2 items on the NSCH that asked about child PA and sports participation. The PA variable asked "During the past week, on how many days did this child exercise, play a sport, or participate in physical activity for at least 60 minutes?" Responses for this item ranged from 0 days (coded 0 ), 1 to 3 days (coded 1), 4 to 6 days (coded 2), and every day (coded 3) and were treated on the ordinal measurement scale. The sports performance predictor variable asked "During the past 12 months, did this child participate in a sports team or did he or she take sports lessons after school or on the weekend?" Reponses for the sports participation item were binary-coded $(0=$ no participation; $1=$ participation $)$.

Important child- and family-level covariates were included in the analysis to adjust for potential confounding associations. Childlevel covariates included child age (6-11 and 12-17 y), child sex (female and male), child body mass index class (underweight, normal weight, overweight, or obese), and child race/ethnicity (White-non-Hispanic, Hispanic, Black-non-Hispanic, other/multiracial-non-Hispanic). Family-level covariates included items regarding highest adult education within household (college degree or higher, some college, high school/GED, less than high school), household poverty level (400\% FPL or greater, 200\%-399\% FPL, 100\%-199\% FPL, 0\%-99\% FPL), and the family structure (2 married parents, 2 unmarried parents, single parent, and grandparent).

\section{Statistical Analysis}

To account for NSCH's complex survey design and use of probability weights, the STATA survey prefix command "svy" was employed to compute weighted prevalence within the descriptive analysis and to compute appropriate variances and confidence intervals within the primary analyses. Unweighted and weighted prevalence statistics were computed for the PA and sports participation predictors in addition for the child- and family-level covariates. The primary analyses consisted of the use of weighted simple and multiple logistic regression models to calculate crude (unadjusted) and adjusted parameter estimates, respectively. Separate models were run for each academic performance dependent variable. Post hoc analyses were employed to examine the joint associations (interactions) between child PA and sports participation on each academic performance variable to determine if the association between PA and a respective dependent variable differed according to sport participation status. To test for age and sex effect modification, subpopulation analyses were employed within the adjusted models using STATA's "svy, subpop:" prefix command. Communication of the results involved the reporting of odds ratios with the associated $95 \%$ confidence intervals. The 2 sided alpha level was set at $P<.05$, and all analyses were conducted using STATA statistical software package (version 15.0; StataCorp, College Station, TX).

\section{Results}

Unweighted and weighted prevalence for all variables are reported in Table 1. During the past 12 months, approximately $10.1 \%$ (weighted prevalence $=9.6 \%$ ) of the parents reported that their child has had serious difficulty concentrating, remembering, or making decisions, and $5.4 \%$ (weighted prevalence $=6.3 \%$ ) reported that their child ever repeated a grade level. Approximately 
Table 1 Counts, Unweighted Prevalence, and Weighted Prevalence Statistics for All Observed Variables

\begin{tabular}{|c|c|c|c|c|}
\hline Variable & Level & Count & Unweighted \% & Weighted \% \\
\hline \multirow[t]{2}{*}{ Difficulty concentrating, remembering, making decisions } & No & 33,270 & 89.9 & 90.4 \\
\hline & Yes & 3748 & 10.1 & 9.6 \\
\hline \multirow[t]{2}{*}{ Repeated a grade level } & No & 34,876 & 94.6 & 93.7 \\
\hline & Yes & 2008 & 5.4 & 6.3 \\
\hline \multirow[t]{4}{*}{$60 \mathrm{~min}$ of $\mathrm{PA}$} & $0 \mathrm{D}$ & 3312 & 9.0 & 9.5 \\
\hline & $1-3 \mathrm{~d} / \mathrm{wk}$ & 14,301 & 38.7 & 39.9 \\
\hline & $4-6 \mathrm{~d} / \mathrm{wk}$ & 11,600 & 31.3 & 28.2 \\
\hline & Every day per week & 7767 & 21.0 & 22.6 \\
\hline \multirow[t]{2}{*}{ Sports participation } & Did not participate & 13,270 & 36.1 & 42.3 \\
\hline & Participated & 23,509 & 63.9 & 57.7 \\
\hline \multirow[t]{2}{*}{ Child age } & 6- to $11-y$ old & 15,896 & 42.5 & 50.0 \\
\hline & 12 - to 17 -y old & 21,496 & 57.5 & 50.0 \\
\hline \multirow[t]{2}{*}{ Child sex } & Male & 19,415 & 51.9 & 51.1 \\
\hline & Female & 17,977 & 48.8 & 48.9 \\
\hline \multirow[t]{3}{*}{ Child BMI class } & Normal weight & 17,310 & 65.9 & 62.5 \\
\hline & Underweight & 1701 & 6.5 & 6.7 \\
\hline & Overweight/obese & 7255 & 27.6 & 30.8 \\
\hline \multirow[t]{4}{*}{ Child race/ethnicity } & White/non-Hispanic & 25,867 & 69.2 & 49.9 \\
\hline & Hispanic & 4377 & 11.7 & 25.7 \\
\hline & Black/non-Hispanic & 2497 & 6.7 & 14.3 \\
\hline & Other/multiracial-non-Hispanic & 4651 & 12.4 & 10.1 \\
\hline \multirow[t]{4}{*}{ Highest adult education } & College degree or higher & 22,195 & 59.4 & 47.3 \\
\hline & Some college & 9063 & 24.3 & 22.3 \\
\hline & High school/GED & 5127 & 13.7 & 19.8 \\
\hline & Less than high school & 1007 & 2.7 & 10.6 \\
\hline \multirow[t]{4}{*}{ Household poverty level } & $0 \%-99 \%$ FPL & 4566 & 12.2 & 20.2 \\
\hline & $100 \%-199 \%$ FPL & 5884 & 15.7 & 21.7 \\
\hline & $200 \%-399 \%$ FPL & 11,248 & 30.8 & 27.1 \\
\hline & $400 \%$ FPL or greater & 15,694 & 42.0 & 31.0 \\
\hline \multirow[t]{4}{*}{ Family structure } & 2 married parents & 25,744 & 70.3 & 64.7 \\
\hline & 2 unmarried parents & 2239 & 6.1 & 8.0 \\
\hline & Single parent & 7108 & 19.3 & 21.3 \\
\hline & Grandparent household & 1262 & 3.4 & 4.4 \\
\hline
\end{tabular}

Abbreviations: BMI, body mass index; FPL, federal poverty level; GED, General Educational Development; PA, physical activity.

$21.0 \%$ (weighted prevalence $=22.6 \%$ ) of the parents reported that their child engaged in 60 minutes of PA every day during the past week, and approximately $63.9 \%$ (weighted prevalence $=57.7 \%$ ) of the parents reported that their child participated in sports during the past 12 months.

Table 2 presents the unadjusted crude odds ratios for predicting each academic performance dependent variable. Any reported child weekly PA frequency associated with $47 \%$ to $64 \%$ lower odds of child difficulty concentrating, remembering, or making decisions compared with no reported child PA $(P<.001)$. Child sports participation associated with $58 \%$ lower odds of reported difficulty concentrating, remembering, or making decisions compared with reported no sports participation $(P<.001)$. In addition, reported child PA of 4 to 6 days per week associated with $37 \%$ lower odds of ever repeating a grade level $(P<.001)$, and sports participation associated with $39 \%$ lower odds of ever repeating a grade level $(P<.001)$.
Table 3 presents the adjusted odds ratios for predicting each academic performance dependent variable. After adjusting for childand family-level covariates, weekly child PA independently associated with $37 \%$ to $46 \%$ lower odds of difficulty concentrating, remembering, or making decisions. Likewise, after adjusting for child- and family-level covariates, child sports participation during the past 12 months independently associated with $53 \%$ lower odds of difficulty concentrating, remembering, or making decisions. No age or sex effect modification was found using the cognitive functioning outcome. In addition, after covariate adjustment, reported weekly child PA and child sports participation during the past 12 months did not independently associate with ever repeating a grade level using the total sample. However, the relationship between sports participation and academic progression was moderated by age, as sports participation associated with $26 \%$ lower odds of ever repeating a grade level in 12- to 17-year-old adolescents 
Table 2 Crude Parameter Estimates Predicting Academic Performance Variables Using Weighted Simple Logistic Regression

\begin{tabular}{|c|c|c|c|}
\hline Predictor & Level & $\begin{array}{l}\text { Difficulty concentrating, } \\
\text { remembering, making decisions } \\
\text { (no= referent) } \\
\text { crude OR }(95 \% \mathrm{Cl})\end{array}$ & $\begin{array}{c}\text { Repeated a grade level } \\
\text { (no = referent) } \\
\text { crude OR }(95 \% \mathrm{Cl})\end{array}$ \\
\hline \multirow[t]{4}{*}{$60 \mathrm{~min}$ of $\mathrm{PA}$} & 0 days & Referent & Referent \\
\hline & $1-3 \mathrm{~d} / \mathrm{wk}$ & $0.53^{\dagger}(0.42-0.67)$ & $0.83(0.62-1.11)$ \\
\hline & $4-6 \mathrm{~d} / \mathrm{wk}$ & $0.36^{\dagger}(0.28-0.46)$ & $0.63^{\dagger}(0.46-0.87)$ \\
\hline & Every day per week & $0.45^{\dagger}(0.34-0.59)$ & $0.93(0.68-1.28)$ \\
\hline \multirow[t]{2}{*}{ Sports participation } & Did not participate & Referent & Referent \\
\hline & Participated & $0.42^{\dagger}(0.37-0.49)$ & $0.61^{\dagger}(0.51-0.74)$ \\
\hline \multirow[t]{2}{*}{ Child age } & 6 - to $11-y$ old & Referent & Referent \\
\hline & $12-$ to $17-y$ old & $0.97(0.84-1.13)$ & $1.63^{\dagger}(1.35-1.98)$ \\
\hline \multirow[t]{2}{*}{ Child sex } & Male & Referent & Referent \\
\hline & Female & $0.58^{\dagger}(0.50-0.68)$ & $0.66^{\dagger}(0.54-0.80)$ \\
\hline \multirow[t]{3}{*}{ Child BMI class } & Normal weight & Referent & Referent \\
\hline & Underweight & $1.59^{\dagger}(1.19-2.11)$ & $1.40(0.95-2.07)$ \\
\hline & Overweight/obese & $1.38^{\dagger}(1.15-1.66)$ & $1.45^{\dagger}(1.14-1.84)$ \\
\hline \multirow[t]{4}{*}{ Child race/ethnicity } & White/non-Hispanic & Referent & Referent \\
\hline & Hispanic & $0.76(0.76-1.22)$ & $1.61^{\dagger}(1.26-2.06)$ \\
\hline & Black/non-Hispanic & $1.26^{\dagger}(1.01-1.57)$ & $2.10^{\dagger}(1.66-2.64)$ \\
\hline & Other/multiracial-non-Hispanic & $0.87(0.71-1.07)$ & $1.07(0.80-1.44)$ \\
\hline \multirow[t]{4}{*}{ Highest adult education } & College degree or higher & Referent & Referent \\
\hline & Some college & $1.57^{\dagger}(1.33-1.84)$ & $2.14^{\dagger}(1.74-2.62)$ \\
\hline & High school/GED & $1.70^{\dagger}(1.41-2.06)$ & $3.08^{\dagger}(2.46-3.87)$ \\
\hline & Less than high school & $1.52^{\dagger}(1.06-2.18)$ & $3.71^{\dagger}(2.62-5.27)$ \\
\hline \multirow[t]{4}{*}{ Household poverty level } & $0 \%-99 \%$ FPL & Referent & Referent \\
\hline & $100 \%-199 \%$ FPL & $0.80(0.63-1.02)$ & $0.78(0.60-1.02)$ \\
\hline & 200\%-399\% FPL & $0.55^{\dagger}(0.44-0.69)$ & $0.44^{\dagger}(0.34-0.58)$ \\
\hline & $400 \%$ FPL or greater & $0.43^{\dagger}(0.35-0.54)$ & $0.28^{\dagger}(0.23-0.36)$ \\
\hline \multirow[t]{4}{*}{ Family structure } & 2 married parents & Referent & Referent \\
\hline & 2 unmarried parents & $1.87^{\dagger}(1.36-2.58)$ & $1.97^{\dagger}(1.43-2.71)$ \\
\hline & Single parent & $1.69^{\dagger}(1.43-1.99)$ & $1.96^{\dagger}(1.58-2.44)$ \\
\hline & Grandparent household & $2.48^{\dagger}(1.73-3.55)$ & $3.34^{\dagger}(2.33-4.78)$ \\
\hline
\end{tabular}

Abbreviations: BMI, body mass index; FPL, Federal Poverty Level; GED, General Educational Development; OR, odds ratio; PA, physical activity; 95\% CI, 95\% confidence interval. Note: Bold values indicate the statistical significance and ${ }^{\dagger}$ statistical significance, $P<.05$.

$(P=.049)$ but not in 6- to 11-year-old children. No sex effect modification was found using the academic progression outcome.

Post hoc analyses consisted of testing the joint associations (interactions) between reported child PA and sports participation on each academic performance dependent variable. Covariates that were found to be statistically significant within the respective adjusted models were controlled for within each post hoc analysis. There was a statistically significant joint association between child PA and sports participation on ever repeating a grade level. The results of this post hoc analysis are illustrated in Figure 1. If a child did not participate in sports within the past 12 months, PA did not significantly associate with ever repeating a grade level. However, among children who were reported to have participated in sports during the past 12 months, reported weekly child PA associated with lower odds of ever repeating a grade level compared with no reported child PA $\left(\mathrm{OR}_{1-3 \mathrm{~d}}=0.52, P_{1-3 \mathrm{~d}}=.004 ; \mathrm{OR}_{4-6 \mathrm{~d}}=0.44\right.$, $\left.P_{4-6 \mathrm{~d}}=.001 ; \mathrm{OR}_{\text {Every day }}=0.53, P_{\text {Every day }}=.003\right)$.

\section{Discussion}

The purpose of this study was to examine the independent and joint associations between PA and sports participation on academic performance variables within a representative sample of US children and adolescents. After controlling for important child- and familylevel covariates, any frequency of child PA during the past week and sports participation during the past 12 months associated with lower odds of reported difficulty concentrating, remembering, or making decisions. Interestingly, sports participation moderated the association between child PA frequency and ever repeating a grade level as any frequency of weekly PA associated with lower odds of ever repeating a grade level only in those children who participated in sports. An interpretation of these results and a discussion of potential future research directions are provided.

Previous research has shown that higher levels of PA associates with specific aspects of academic performance in children and 
Table 3 Adjusted Parameter Estimates Predicting Academic Performance Variables Using Weighted Multiple Logistic Regression

\begin{tabular}{|c|c|c|c|}
\hline Predictor & Level & $\begin{array}{l}\text { Difficulty concentrating, } \\
\text { remembering, making decisions } \\
(\mathrm{no}=\text { referent) } \\
\text { adjusted OR }(95 \% \mathrm{Cl})\end{array}$ & $\begin{array}{c}\text { Repeated a grade level } \\
\text { (no = referent) } \\
\text { adjusted OR }(95 \% \mathrm{Cl})\end{array}$ \\
\hline \multirow[t]{4}{*}{60 min of PA } & 0 days & Referent & Referent \\
\hline & $1-3 \mathrm{~d} / \mathrm{wk}$ & $0.63^{\dagger}(0.49-0.79)$ & $1.02(0.73-1.44)$ \\
\hline & $4-6 \mathrm{~d} / \mathrm{wk}$ & $0.52^{\dagger}(0.39-0.71)$ & $1.00(0.65-1.52)$ \\
\hline & Every day per week & $0.54^{\dagger}(0.39-0.76)$ & $1.20(0.80-1.82)$ \\
\hline \multirow[t]{2}{*}{ Sports participation } & Did not participate & Referent & Referent \\
\hline & Participated & $0.47^{\dagger}(0.39-0.57)$ & $0.84(0.63-1.11)$ \\
\hline \multirow[t]{2}{*}{ Child age } & 6 - to $11-y$ old & Referent & Referent \\
\hline & 12 - to $17-y$ old & $0.83(0.66-1.05)$ & $1.18(0.88-1.60)$ \\
\hline \multirow[t]{2}{*}{ Child sex } & Male & Referent & Referent \\
\hline & Female & $0.55^{\dagger}(0.45-0.66)$ & $0.65^{\dagger}(0.51-0.82)$ \\
\hline \multirow[t]{3}{*}{ Child BMI class } & Normal weight & Referent & Referent \\
\hline & Underweight & $1.39^{\dagger}(1.02-1.89)$ & $1.13(0.72-1.77)$ \\
\hline & Overweight/obese & $1.14(0.93-1.39)$ & $1.14(0.89-1.48)$ \\
\hline \multirow[t]{4}{*}{ Child race/ethnicity } & White/non-Hispanic & Referent & Referent \\
\hline & Hispanic & $0.96(0.57-1.01)$ & $1.08(0.80-1.46)$ \\
\hline & Black/non-Hispanic & $0.85(0.66-1.10)$ & $1.44^{\dagger}(1.07-1.94)$ \\
\hline & Other/multiracial-non-Hispanic & $0.79(0.61-1.03)$ & $1.11(0.78-1.59)$ \\
\hline \multirow[t]{4}{*}{ Highest adult education } & College degree or higher & Referent & Referent \\
\hline & Some college & $1.21(0.99-1.48)$ & $1.69^{\dagger}(1.32-2.16)$ \\
\hline & High school/GED & $0.98(0.75-1.29)$ & $1.90^{\dagger}(1.41-2.56)$ \\
\hline & Less than high school & $0.81(0.48-1.36)$ & $2.22^{\dagger}(1.35-3.62)$ \\
\hline \multirow[t]{4}{*}{ Household poverty level } & 0\%-99\% FPL & Referent & Referent \\
\hline & $100 \%-199 \%$ FPL & $0.93(0.66-1.28)$ & $0.81(0.58-1.17)$ \\
\hline & $200 \%-399 \%$ FPL & $0.70^{\dagger}(0.53-0.93)$ & $0.56^{\dagger}(0.40-0.79)$ \\
\hline & $400 \%$ FPL or greater & $0.73^{\dagger}(0.56-0.96)$ & $0.50^{\dagger}(0.36-0.67)$ \\
\hline \multirow[t]{4}{*}{ Family structure } & 2 married parents & Referent & Referent \\
\hline & 2 unmarried parents & $1.44(0.95-2.17)$ & $1.35(0.89-2.05)$ \\
\hline & Single parent & $1.38^{\dagger}(1.12-1.70)$ & $1.22(0.94-1.61)$ \\
\hline & Grandparent household & $1.73^{\dagger}(1.15-2.61)$ & $2.47^{\dagger}(1.54-3.95)$ \\
\hline
\end{tabular}

Abbreviations: BMI, body mass index; FPL, Federal Poverty Level; GED, General Educational Development; OR, odds ratio; PA, physical activity; 95\% CI, 95\% confidence interval. Note: Bold values denote the statistical significance and ${ }^{\dagger}$ statistical significance, $P<.05$.

adolescents. ${ }^{27-29}$ However, not all research shows this favorable pattern with null associations observed in a number of longitudinal and experimental studies. ${ }^{30-32}$ Singh et al $^{32}$ found that between $48 \%$ and $60 \%$ of high-quality studies showed a beneficial impact of PA on specific academic performance variables. However, 6 out of 7 high-quality studies $(86 \%)$ showed a beneficial effect of PA on mathematics performance. ${ }^{32}$ These contrasting results from previous work highlight that there may be important moderators and mediators of effect when considering the relationship between PA and academic performance and that this relationship also differs by the type of academic outcomes examined (eg, cognitive skills, behavior, and subject achievement). The novelty of the current study is the consideration of multiple aspects of academic performance and examination of both PA and sports participation together within the analysis. The results of this study indicate that both PA and sports participation are independently associated with lower odds of difficulty concentrating, remembering, and making decisions, an item on the $\mathrm{NSCH}$ that relates to executive control, which is a core cognitive process including inhibition, working memory, and cognitive flexibility. ${ }^{33,34}$ These cognitive skills are needed to complete complex goal-directed cognitive tasks that are often undertaken in academic settings.

The results support prior research identifying the role of PA on specific cognitive skills and also show that this relationship is independent of sports participation and several child- and familylevel potential confounding variables. ${ }^{27,35}$ The current study also found an independent association between sports participation and cognitive functioning, a relationship found in other work, ${ }^{36-39}$ and an independent association between sports participation and academic progression in older adolescents only. Bang et $\mathrm{al}^{37}$ found that sports participation had positive effects on locus of control, or how well an individual feels that they are in control of their life, which may contribute to better academic performance. This improved locus of control may relate to the structured characteristic of sports participation. The social aspect of sports participation also may improve social ties between individuals and limit antisocial 


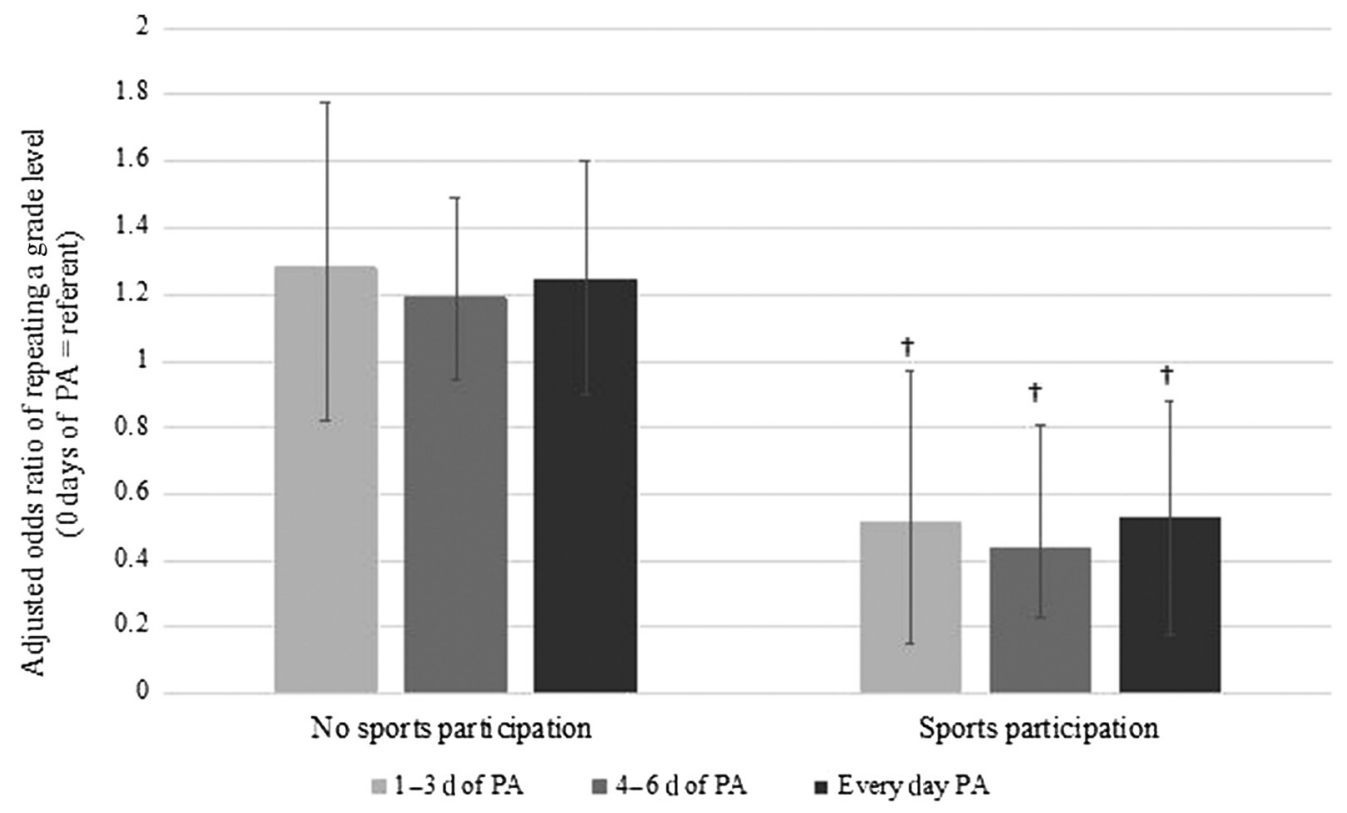

Figure 1 - Joint association of reported weekly child PA frequency and sports participation on adjusted ORs of ever repeating a grade level. Note: odds ratio referent $=1$; odds ratios adjusted for child sex, race/ethnicity, adult education, family Federal Poverty Level, and family structure. OR indicates odds ratio; PA, physical activity. ${ }^{\dagger}$ Statistical differences in odds ratios between sport participation groups within a respective PA stratum, $P<.05$.

behaviors within individuals. ${ }^{40,41}$ These social relations may, in turn, promote self-confidence, social interactions, and reciprocal modeling and learning among higher-achieving individuals. ${ }^{40,41}$ Thus, both the structured and social characteristics of sport may positively influence the skills needed for academic success. However, the independent association between sports participation and academic progression was only found in older adolescents. A possible mechanism for this may be that within the higher grade levels, adolescents who fail a grade may not be allowed to participate in sports. In addition, athletes who compete in highly competitive sports programs may enroll in less challenging coursework to cope with concurrent academic and athletic priorities. These plausible mechanisms suggest potential bidirectionality between sports participation and academic progression and, thus, it should be explored with future research.

A novel result found from this study was the joint association between reported PA frequency and sports participation with ever repeating a grade level. Children who participated in any frequency of PA and participated in sports had lower odds of ever repeating a grade level. The PA did not associate with repeating a grade level if the child did not participate in sports. Domazet et $\mathrm{al}^{40}$ examined if PA, sports participation, or active commuting associated with mathematics performance and inhibitory control in a sample of adolescents. The PA's associations with academic performance were mixed, but sports participation significantly associated with higher mathematics performance. ${ }^{41}$ However, no joint associations were tested. Fox et $\mathrm{al}^{41}$ also examined the associations between PA and sports team participation on grade point average among middle- and high-school students and found that both PA and sports participation had significant associations with grade point average with the associations differing by grade level and sex. Again, however, joint associations between PA and sports participation were not tested. ${ }^{41}$ The statistically significant joint associations in the current study suggests, perhaps, that structured PA with social relations, as seen in sports, is a type of PA that may more strongly influence academic achievement. To the authors' knowledge, this is the first study to observe these findings. Despite the statistical control for a number of child- and family-level covariates, this joint association should be interpreted with caution because of the cross-sectional design and use of survey methods for data collection. However, this unique finding could spur additional research.

This study provides an evidence of both independent and joint associations between reported PA and sports participation with specific aspects of academic performance. However, the broadness of the PA and sports participation items on the NSCH manifests a need for additional research on these associations. Specifically, examining the intensity of PA and participation in different types of sports (eg, team vs individual) will provide important and specific information. Possible other factors to consider within these relationships are the time segment characteristics of these behaviors (eg, weekday, weekend, in school, out of school), how relative time use of PA intensity associates with specific aspects of academic performance within a compositional data analytic framework, the frequency of sports participation, and the interaction between motor skill competency, sports participation, and academic performance. Studies have also shown that children from lower income households have a lower prevalence of sports participation compared with children from higher income households. ${ }^{42}$ Using the current 2017-2018 NSCH sample, there was a relationship between family poverty level and sports participation, as households at $400 \%$ FPL or greater had 4.8 times greater odds of child sports participation compared with households at $0 \%$ to $100 \%$ of FPL. Family poverty level was controlled for within the analyses in the current study; however, the strong association between family poverty level and sports participation provides additional evidence for the imperative need to provide sports participation opportunities for children within lower income families. Important socioenvironmental facilitators to provide these opportunities may be parents and peers, which may mitigate barriers for children's sport participation. ${ }^{43}$ Most importantly, examining these associations using longitudinal and experimental research designs will provide evidence for causal influences, and testing for bidirectional 
relationships among these constructs using cross-lagged panel models may have merit.

This study has several strengths to highlight. First, this study included a large and representative sample of US children and adolescents; thus, the generalizability of findings from this study is not limited. Second, this study included 2 separate dependent variables that constitute academic performance. The study also examined the influence of both PA and sports participation on academic performance; most studies tend to examine only one of these explanatory/predictor variables. Third, the associations examined in this study were adjusted for a number of child- and familylevel covariates, attenuating the potential confounding influence of these factors. Finally, the analyses conducted in this study included the combined data from 2 consecutive years of the NSCH, which improves statistical power and provides more precise parameter estimates compared with the use of 1-year data. Limitations of the current study included the use of parent self-report, which may be subject to both recall and response bias. The NSCH is an annual cross-sectional survey; therefore, all relationships are correlational and no causal inferences can be made. In addition, the PA dependent variable only asked about meeting the weekly frequency of the 60minute-per-day guideline but did not specifically ask about PA intensity. Finally, the academic performance variables were dichotomized for analysis, precluding trend analyses across multiple levels of a respective variable and the examination of possible $U$-shaped associations within the data.

\section{Conclusions}

This study provided information on the relationships among PA, sports participation, and academic performance within a representative sample of US children and adolescents. Both PA and sports participation independently and negatively associated with reported difficulty concentrating, remembering, or making decisions. Most interestingly, the negative relationship between PA and repeating a grade level was moderated by sports participation; that is, any reported weekly PA associated with lower odds of repeating a grade level in children who participated in sports. These results indicate that PA and sports participation both may influence specific aspects of a child's academic performance. Future research should examine these associations using more objective measures within longitudinal and experimental research designs. Determining the types of sports that may more strongly influence academic performance may also have merit in future work. Both PA and sports participation should be considered when utilizing movement-based behaviors to improve specific aspects of academic performance in youth.

\section{Acknowledgments}

The authors would like to thank the parents who participated in either the 2017 or the $2018 \mathrm{NSCH}$. No funding was received for this study.

\section{References}

1. Castelli DM, Hillman CH, Hirsch J, Hirsch A, Drollette E. FIT Kids: time in target heart zone and cognitive performance. Prev Med. 2011;52:S55-S59. PubMed ID: 21281671 doi:10.1016/j.ypmed. 2011.01.019

2. Brusseau TA, Burns RD. Physical activity, health-related fitness, and classroom behavior in children: a discriminant function analysis. Res
Q Exerc Sport. 2018;89(4):411-417. PubMed ID: 30285569 doi:10. 1080/02701367.2018.1519521

3. Donnelly JE, Hillman CH, Castelli D, et al. Physical activity, fitness, cognitive function, and academic achievement in children: a systematic review. Med Sci Sports Exerc. 2016;48(6):1197-1222. PubMed ID: 27182986 doi:10.1249/MSS.0000000000000901

4. Stillman CM, Cohen J, Lehman ME, Erickson KI. Mediators of physical activity on neurocognitive function: a review at multiple levels of analysis. Front Hum Neurosci. 2016;10:626. PubMed ID: 28018195 doi:10.3389/fnhum.2016.00626

5. van Praag H. Neurogenesis and exercise: past and future directions. Neuromolecular Med. 2008;10(2):128-140. PubMed ID: 18286389 doi:10.1007/s12017-008-8028-z

6. Hillman CH, Khan NA, Kao SC. The relationship of health behaviors to childhood cognition and brain health. Ann Nutr Metab. 2015; 66(3):1-4. PubMed ID: 26088038 doi:10.1159/000381237

7. Hillman CH, Erickson KI, Hatfield BD. Run for your life! Childhood physical activity effects on brain and cognition. Kinesiol Rev. 2017;6(1):12-21. doi:10.1123/kr.2016-0034

8. Benzing V, Chang YK. Acute physical activity enhances executive functions in children with ADHD. Sci Rep. 2018;8(1):12382. PubMed ID: 30120283 doi:10.1038/s41598-018-30067-8

9. Goh TL, Hannon JC, Webster C, Podlog L, Newton M. Effects of a TAKE 10! Classroom-based physical activity intervention on third to fifth grade children's on-task behavior. $J$ Phys Act Health. 2016;13(7):712-718. PubMed ID: 26800566 doi:10.1123/jpah. 2015-0238

10. Stylianou M, Kulinna PH, van der Mars H, Mahar MT, Adams MA, Amazeen E. Before-school running/walking club: effects on student on-task behavior. Prev Med Rep. 2016;3:196-202. PubMed ID: 27419015 doi:10.1016/j.pmedr.2016.01.010

11. Kulinna PH, Stylianou M, Dyson B, Banville B, Dryden C, Colby R. The effect of an authentic acute physical education session of dance on elementary students' selective attention. Biomed Res Int. 2018;2018:8790283. PubMed ID: 29662903 doi:10.1155/2018/ 8790283

12. Watson A, Timperio A, Brown H, Best K, Hesketh KD. Effect of classroom-based physical activity interventions on academic and physical activity outcomes: a systematic review and meta-analysis. Int J Behav Nutr Phys Act. 2017;14(1):114. PubMed ID: 28841890 doi:10.1186/s12966-017-0569-9

13. Rasberry CN, Lee SM, Robin L, et al. The association between school-based physical activity, including physical education, and academic performance: a systematic review of the literature. Prev Med. 2011;52:S10-S20. PubMed ID: 21291905 doi:10.1016/j .ypmed.2011.01.027

14. Gould D. The current youth sport landscape: identifying critical research issues. Kinesiol Rev. 2019;8(3):150-161. doi:10.1123/kr. 2019-0034

15. Clark HJ, Camire M, Wade TJ, Cairney J. Sport participation and its association with social and psychological factors known to predict substance use and abuse among youth: a scoping review of the literature. Int Rev Sport Exerc Psychol. 2015;8(1):224-250. PubMed ID: 26692895 doi:10.1080/1750984X.2015.1068829

16. Zwinkels M, Verschuren O, Balemans A, et al. Effects of a schoolbased sports program on physical fitness, physical activity, and cardiometabolic health in youth with physical disabilities: data from the Sport-2-Stay-Fit Study. Front Pediatr. 2018;6:75. PubMed ID: 29632853 doi:10.3389/fped.2018.00075

17. Subramanian SK, Sharma VK, Arunachalam V, Radhakrishnan K, Ramamurthy S. Effect of structured and unstructured physical activity training on cognitive functions in adolescents — a randomized control 
trial. J Clin Diagn Res. 2015;9(11):CC04-CC09. PubMed ID: 26675059

18. Burns RD, Brusseau TA, Pfledderer CD, Fu Y. Sports participation correlates with academic achievement: results from a large adolescent sample within the 2017 US National Youth Risk Behavior Survey. Percept Mot Skills. 2020;127(2):448-467. PubMed ID: 31937186 doi:10.1177/0031512519900055

19. Child and Adolescent Health Measurement Initiative (CAHMI). 2017-2018 National Survey of Children's Health (2 Years Combined Data Set): Child and Family Health Measures, National Performance and Outcome Measures, and Subgroups, STATA Codebook, Version 1.0. Data Resource Center for Child and Adolescent Health supported by Cooperative Agreement U59MC27866 from the U.S. Department of Health and Human Services, Health Resources and Services Administration (HRSA), Maternal and Child Health Bureau (MCHB). www.childhealthdata.org. Accessed October 7, 2019.

20. Child and Adolescent Health Measurement Initiative. 2018 National Survey of Children's Health, Sampling and Survey Administration. Data Resource Center for Child and Adolescent Health, supported by Cooperative Agreement 1-U59-MC06980-01 from the U.S. Department of Health and Human Services, Health Resources and Services Administration (HRSA), Maternal and Child Health Bureau (MCHB). www.childhealthdata.org. Accessed October 7, 2019.

21. Jaeschke L, Steinbrecher A, Luzak A, et al. Socio-cultural determinants of physical activity across the life course: a 'Determinants of Diet and Physical Activity' (DEDIPAC) umbrella systematic literature review. Int J Behav Nutr Phys Act. 2017;14(1):173. PubMed ID: 29262864 doi:10.1186/s12966-017-0627-3

22. Stanley RM, Ridley K, Dollman J. Correlates of children's timespecific physical activity: a review of the literature. Int J Behav Nutr Phys Act. 2012;9(1):50. PubMed ID: 22546218 doi:10.1186/14795868-9-50

23. Liu J, Probst JC, Harun N, Bennett KJ, Torres ME. Acculturation, physical activity, and obesity among Hispanic adolescents. Ethn Health. 2009;14(5):509-525. PubMed ID: 19404878 doi:10.1080/ 13557850902890209

24. Muthuri SK, Onywera VO, Tremblay MS, et al. Relationships between parental education and overweight with childhood overweight and physical activity in 9-11 year old children: results from a 12 country study. PLoS One. 2016;11(8):e0147746. PubMed ID: 27557132 doi:10.1371/journal.pone.0147746

25. Min J, Xue H, Wang Y. Association between household poverty dynamics and childhood overweight risk and health behaviours in the United States: an 8-year nationally representative longitudinal study of 16800 children. Pediatr Obes. 2018;13(10):590-597. PubMed ID: 30110714 doi:10.1111/ijpo.12292

26. Langøy A, Smith ORF, Wold B, Samdal O, Hang EM. Associations between family structure and young people's physical activity and screen time behaviors. BMC Public Health. 2019;19(1):433. PubMed ID: 31023280 doi:10.1186/s12889-019-6740-2

27. Hillman CH, Pontifex MB, Castelli DM, et al. Effects of the FITKids randomized controlled trial on executive control and brain function. Pediatrics. 2014;134(4):e1063-e1071. PubMed ID: 25266425 doi:10.1542/peds.2013-3219

28. Álvarez-Bueno C, Pesce C, Cavero-Redondo I, Sánchez-López M, Garrido-Miguel M, Martínez-Vizcaíno V. Academic achievement and physical activity: a meta-analysis. Pediatrics. 2017;140(6): e20171498. PubMed ID: 29175972 doi:10.1542/peds.2017-1498
29. Burns RD, Fu Y, Brusseau TA, Clements-Nolle K, Yang W. Relationships among physical activity, sleep duration, diet, and academic achievement in a sample of adolescents. Prev Med Rep. 2018;12: 71-74. PubMed ID: 30191095 doi:10.1016/j.pmedr.2018.08.014

30. Mcloughlin G, Bai Y, Welk GJ. Longitudinal associations between physical fitness and academic achievement in youth. Med Sci Sports Exerc. 2020;52(3):616-622. PubMed ID: 31524831 doi:10.1249/ MSS.0000000000002159

31. Calvert HG, Barcelona JM, Melville D, Turner L. Effects of acute physical activity on NIH tool-box-measured cognitive functions among children in authentic education settings. Ment Health Phys Act. 2019;17:100293. doi:10.1016/j.mhpa.2019.100293

32. Singh AS, Saliasi E, van den Berg V, et al. Effects of physical activity interventions on cognitive and academic performance in children and adolescents: a novel combination of a systematic review and recommendations from an expert. Br J Sports Med. 2019;53(10):640-647. PubMed ID: 30061304 doi:10.1136/bjsports-2017-098136

33. Pessoa L. How do emotion and motivation direct executive control? Trends Cogn Sci. 2009;13(4):160-166. PubMed ID: 19285913 doi:10.1016/j.tics.2009.01.006

34. Clair-Thompson HLS, Gathercole S.E. Executive functions and achievements in school: shifting, updating, inhibition and working memory. $Q J$ Exp Psychol. 2006;59(4):745-759. doi:10.1080/ 17470210500162854

35. Phillips DS, Hannon JC, Gregory BB, Burns RD. Effect of vigorous physical activity on executive control in middle school students. Int $J$ Environ Res Public Health. 2019;16(20):3949. doi:10.3390/ ijerph16203949

36. Rees DI, Sabia JJ. Sports participation and academic performance: evidence from the National Longitudinal Study of Adolescent Health. Econ Educ Rev. 2010;29(5):751-759. doi:10.1016/j.econedurev. 2010.04.008

37. Bang H, Chang M, Lee C, Kim S, Taliaferro A. Sport participation, locus of control, and academic performance among early adolescents: racial and linguistic status differences. Sociol Spectr. 2019;39(1):2039. doi:10.1080/02732173.2018.1564098

38. Munoz-Bullon F, Sanchez-Bueno MJ, Vos-Saz A. The influence of sports participation on academic performance among students in higher education. Sport Manage Rev. 2017;20(4):365-378.

39. Covay E, Carbonaro W. After the bell: participation in extracurricular activities, classroom behavior, and academic achievement. Sociol Educ. 2010;83(1):20-45. doi:10.1177/0038040709356565

40. Domazet SL, Tarp J, Huang T, et al. Associations of physical activity, sports participation and active commuting on mathematic performance and inhibitory control in adolescents. PLoS One. 2016;11(1): e0146319. PubMed ID: 26727211 doi:10.1371/journal.pone. 0146319

41. Fox CK, Barr-Anderson D, Neumark-Sztainer D, Wall M. Physical activity and sports team participation: associations with academic outcomes in middle and high school students. J Sch Health. 2010; 80(1):31-37. PubMed ID: 20051088 doi:10.1111/j.1746-1561.2009. 00454.x

42. Wijtzes AI, Jansen W, Bouthoorn SH, et al. Social inequalities in young children's sports participation and outdoor play. Int J Behav Nutr Phys Act. 2014;11(1):155. doi:10.1186/s12966-014-0155-3

43. Duncan SC, Strycker LA, Chaumeton NR. Personal, family and peer correlates of general and sport physical activity among African American, Latino, and White girls. J Health Dispar Res Pract. 2015;8(2):12-28. PubMed ID: 26185734 